\title{
Serum Human Epididymus Protein-4 (HE4) as a Biomarker in Ovarian Cancer and its Comparison with CA-125 in Benign and Malignant Cases
}

\author{
Swarnima Singh ${ }^{1}$, Narayan Singh Jyala ${ }^{2}$, Uday Kumar ${ }^{3}$, Rekha Kumari ${ }^{4}$
}

\begin{abstract}
Introduction: Ovarian cancer is the third leading site of cancer among women in India. $70 \%$ of ovarian cancers are diagnosed with advanced disease leading to high fatality rate. Human epididymis protein 4 (HE4), also known as WAP four disulphide core 2 (WFDC2), is a novel protein and is one of the more promising biomarkers for improving diagnostic performance in ovarian cancer detection.

Aim: To evaluate a new tumor marker, HE4, in comparison with CA-125 in diagnosis of ovarian cancer and benign gynecological diseases.

Material and Methods: Pre-operative serum HE4 and CA-125 were determined in 146 patients with benign gynecologic diseases and 100 patients with malignant gynecologic cancers (64 were epithelial ovarian cancers patients). HE4 and CA-125 cutoffs were 140 pmol/L and 35 kU/L, respectively. Sandwich Elisa, biotin-labelled antibody kit was used for HE4.

Results: HE4 demonstrated better specificity than CA 125 in benign gynecologic disease patients, with abnormal concentrations in $1.3 \%$ and $33.6 \%$, respectively. A significantly higher area under the ROC curve was obtained with HE4 than with CA 125 in the differential diagnosis of gynecologic diseases ( 0.875 vs $0.723 ; p=0.0001)$. Both markers were clearly related to stage (HE4:p=0.004; CA-125: $p=0.001)$ ). and histopathological type (HE4: $p=0.003$ and CA-125: $p=0.009$ in serous papillary ovarian cancer).

Conclusion: HE4 has significantly higher diagnostic specificity than CA 125, and the combination of CA-125 and HE4 improved the detection of ovarian cancer in all stages and histological types. HE4 use may be important in the differential diagnosis of ovarian cancer.

Keywords: Biomaker, Carbohydrate antigen125, HE4, Human epididymis protein 4, Ovarian cancer.

Indian Journal of Medical Biochemistry (2019): 10.5005/jp-journals-10054-0095
\end{abstract}

Ovarian cancer is the most lethal gynecological cancer. In India, ovarian cancer is the third leading site of cancer among women, trailing behind cervix and breast cancer. The age-adjusted incidence rates of ovarian cancer vary between 1.7 and 15.2 per 100,000 population in different parts of the country. An increasing trend of this cancer has been observed since 1982 to date. ${ }^{1}$

Ovarian cancer is primarily diagnosed in the post-menopausal women of the age group 55-64 years; $90 \%$ of the tumors are epithelial in origin..$^{2-5}$ Germ cell tumor, usually diagnosed in the 20s, and sex cord stromal tumors which can be diagnosed at any age, form the remaining $10 \%$ of the ovarian tumors. ${ }^{6}$ Early course of the disease is asymptomatic and late stage disease symptoms are non-specific. Consequently, $>75 \%$ of the tumors are diagnosed at an advanced stage. Mortality parallels disease stage: stages I and II have $>70 \%$ of 5 year survival rate which drastically falls to $<20 \%$ in stages III and IV. ${ }^{7}$ Early detection when tumors are small and still confined to the ovaries represents the best hope for mortality reduction and long term disease control.

CA-125 is the most commonly utilized tumor marker in ovarian carcinoma. CA-125 levels in conjunction with the imaging data and patient's medical and clinical findings are used to differentiate a benign from a malignant adnexal mass. Ultrasound and computed tomography scans though important, but equipments, experience and proper training may not be available at all centers in a developing country. Measuring serum CA-125 levels are more feasible but CA-125 concentrations are also increased in several benign gynecologic conditions like ovarian cysts, myomas and endometriosis. ${ }^{7-10,11}$ Likewise, benign effusions, renal or liver failure

\footnotetext{
${ }^{1}$ Senior Resident, ${ }^{2}$ Professor, ${ }^{3}$ Professor and HOD,

${ }^{4}$ Additional Professor

1,3,4 Department of Biochemistry, IGIMS, Patna, Bihar, India

2Department of Biochemistry, HIMS, Dehradun, Uttarakhand, India
}

Corresponding Author: Swarnima Singh, Senior Resident, Department of Biochemistry, IGIMS, Patna, Bihar, India, e-mail: drswarnimasingh@outlook.com

How to cite this article: Singh S, Jyala NS, Kumar U, Kumari R. Serum Human Epididymus Protein-4 (HE4) as a Biomarker in Ovarian Cancer and its Comparison with CA-125 in Benign and Malignant Cases. Indian J Med Biochem 2019;23(2):242-246.

Source of support: Nil

Conflict of interest: None

and even pregnancy and menstrual cycles have an influence on the CA-125 concentrations. ${ }^{11-13}$ This highlights the need of a simple, inexpensive biomarker that can be used alone or in combination with CA-125 to improve its sensitivity and specificity.

Some markers, including mesothelin, CA-72-4, inhibin, kallikreins, and osteopontin, have been investigated to complement CA-125 and to improve its sensitivity for early detection. Among these human epididymis protein 4 (HE4), is one of the most promising markers with better sensitivity and specificity than CA-125 for gynecological malignancies. It is a protein initially identified in the epithelium of the distal epididymis and may be involved in sperm maturation; it is also called WFDC2 because of its molecular structure, containing 2 whey acid protein domains and

() The Author(s). 2019 Open Access This article is distributed under the terms of the Creative Commons Attribution 4.0 International License (https://creativecommons. org/licenses/by-nc/4.0/), which permits unrestricted use, distribution, and non-commercial reproduction in any medium, provided you give appropriate credit to the original author(s) and the source, provide a link to the Creative Commons license, and indicate if changes were made. The Creative Commons Public Domain Dedication waiver (http://creativecommons.org/publicdomain/zero/1.0/) applies to the data made available in this article, unless otherwise stated. 
a 4-disulfide-bond core with 8 cysteine residues. HE4 is expressed in the normal epithelium lining the male and female genital tracts (but not in normal ovarian epithelium), upper respiratory tract, and ducts of the salivary glands and breast, kidneys, gastrointestinal tract and endometrium. HE4 is strongly upregulated and overexpressed in ovarian carcinomas. ${ }^{14}$ Pathological conditions like lung adenocarcinomas, cystic fibrosis lungs, endometrial cancer, breast cancer, transitional cell carcinomas may also show overexpression. $^{14-16}$

This study was undertaken (1) to evaluate serum HE4 concentrations in benign and malignant gynecologic diseases (2) to explore the clinical usefulness of HE4 (3) to compare the diagnostic performance of HE4 with that of CA-125.

\section{Material and Methods}

246 patients (146 benign gynecological cases, 100 malignant gynecological cases) were enrolled after approval from the Ethics Committee. The inclusion criteria were: patients diagnosed with a pelvic mass of suspected ovarian origin, availability of complete clinical records, informed consent and agreement to have additional testing for new markers, clinical and histological diagnosis with staging and grading of ovarian cancer, where required.

Exclusion criteria were: pregnancy, and significant concomitant diseases such as chronic heart failure, and severe chronic liver or renal disease.

Blood samples were collected in serum separator tube (SST) and allowed to clot for 30 minutes at room temperature before centrifugation for 15 minutes at $1000 \times \mathrm{g}$. Serum was removed, aliquoted and stored at $\leq-20^{\circ} \mathrm{C}$, for analysis within 3 months.

CA-125 was measured on Beckman coulter Access 2 immunoassay based on chemiluminiscence.. Cut off was $35 \mathrm{kU} / \mathrm{L}$. Serum HE4 concentrations were measured using solid phase quantitative sandwich enzyme immunoassay technique $(\mathrm{RnD}$ Systems). Assay was run according to manufacturer's protocol. Cut off for HE4 was 140 pmol/L. Serum creatinine concentrations were measured in all the participants (patients and controls) by use of Jaffe's alkaline picrate method on AU400 (Olympus Diagnostics); values below $1.3 \mathrm{mg} / \mathrm{dL}(115 \mu \mathrm{mol} / \mathrm{L})$ were defined to be within the reference range. All the other relevant clinical information were taken from patient's file.

\section{Statistical Analysis}

Data was analyzed on Excel and SPSS 21.0 software. Median values were calculated for skewed data. Mann-Whitney $U$ test and Kruskall-Wallis test were used to compare the statistical significance between categories. The level of significance was set at $p<0.05$. ROC curves were drawn to assess and compare the roles of HE4 and CA-125.

\section{Results}

\section{Patient Characteristics}

The serum of 246 patients were analyzed: 146 (59.3\%) had benign disease and 100 (40.7\%) had malignant disease. Benign gynecologic group was younger and evidently premenopausal. Malignant gynecologic group was comparatively older, more likely to be post menopausal and having a family history of ovarian or breast cancer (Table 1).

\section{Tumor Characteristics}

The most common benign ovarian tumours were ovarian cysts (cystadenomas $(n=48)$, cystadenofibromas $(n=24)$, endometriomas $(n=33)$, fibroids $(n=29)$ and endometrial polyps $(n=06)$. Other benign tumors (06) encountered were mature teratoma (02), hydrosalpinx (01), functional cyst (01), struma ovarii (01), leydig cell tumor (01). Amongst 100 gynecological cancers: epithelial ovarian cancers (EOC) (64), endometrial cancers (17), endocervical cancers (10), squamous cell carcinoma (09). Most of the EOC were of high grade and were diagnosed at an advanced stage (Table 2).

\section{Tumor Marker Levels}

Interestingly, HE4 showed a higher diagnostic specificity than CA15 in benign gynecologic disease patients. Only $1.3 \%$ of the benign gynecologic disease patients had HE4 concentrations above the reference interval, compared to $33.6 \%$ for CA-125 (Tables 3 and 4).

In malignant samples the median (SE) concentration of HE4 was 116.8 (25.4) pmol/L and of CA 125 was 44.2 (47.9) kU/L. The most common malignancy for which patients exhibited increased concentrations of HE4 and CA 125 was epithelial ovarian cancer (75.2\% and $80 \%$ of samples, respectively). Significantly higher HE4 ( $p=0.001)$ and CA $125(p=0.01)$ serum concentrations were found in patients with ovarian cancer than in patients with other gynecologic cancers $(p=0.001)$ (Table 5$)$.

Table 6 shows the serum HE4 and CA-125 concentrations in different stages and histological types of ovarian cancer patients, excluding 1 patient with renal failure. Both HE4 and CA-125 were well-related to the tumor stage with significantly higher concentrations in stages III and IV (HE4: $p=0.004 ; C A-125: p=0.001$ ) than in stages I and II. Both the markers, however, did not show

Table 1: Patient characteristics

\begin{tabular}{lllll}
\hline Variable & Numerical display & Benign gynecologic ds & Malignant gynecologic ds & $P$ value \\
\hline Number of cases & $\mathrm{n}(\%)$ & $146(59.3)$ & $100(40.7)$ & NA \\
Age in years & Mean (SD) & $46.3(16.0)$ & $57.8(12.6)$ & $<0.001$ \\
Post menopausal & $\mathrm{n} \%$ & $55 / 146(37.7)$ & $74 / 100(74.0)$ & $<0.001$ \\
Smoking & $\mathrm{n} \%$ & $33 / 146(22.6)$ & $19 / 100(19.0)$ & 0.457 \\
Oral Contraceptives & $\mathrm{n} \%$ & $46 / 146(31.5)$ & $30 / 100(30.0)$ & 0.682 \\
HRT & $\mathrm{n} \%$ & $24 / 146(16.4)$ & $08 / 100(08.0)$ & 0.053 \\
F/H BC & $\mathrm{n} \%$ & $23 / 146(15.7)$ & $26 / 100(26.0)$ & 0.009 \\
F/H OC & $\mathrm{n} \%$ & $03 / 146(2.1)$ & $05 / 100(05.0)$ & 0.028 \\
\hline
\end{tabular}

HRT, hormone replacement therapy; F/H, family history; BC, Breast carcinoma; OC, ovarian carcinoma 
Table 2: Tumor characteristics- histolological type and distribution

\begin{tabular}{ll}
\hline Benign gynecologic disease & \\
\hline Cystadenoma/cystadenofibroma & 72 \\
Endometriosis & 33 \\
Fibroids & 29 \\
Endometrial polyps & 06 \\
Mature teratoma & 02 \\
Hydrosalpinx & 01 \\
Functional cyst & 01 \\
Struma ovarii & 01 \\
Leydig cell tumor & 01 \\
Total & 146 \\
\hline Malignant ovarian disease & \\
\hline Epithelial ovarian cancers & 64 \\
Endometrial cancers & 17 \\
Endocervical cancers & 10 \\
Sq. cell carinoma cervix & 09 \\
Total & 100 \\
\hline FIGO stage-(only for EOC) &
\end{tabular}

significant differences between stage III and IV. For stages I-II, HE4 and CA-125 individually demonstrated a sensitivity of $58.3 \%$ and $50 \%$ respectively, which on combination increased to $75 \%$. Likewise, for stages III and IV, sensitivity on combination approached to $96 \%$. Serum concentrations of HE4 $(p=0.009)$ and CA-125 $(p=0.003)$ were significantly higher in serous papillary ovarian tumor than other histological types. Diagnostic sensitivity on combination, improved across all histological types and both markers were well-related to the histological type of ovarian cancer.

\section{ROC Curves}

ROC curves were plotted to compare the diagnostic performances of HE4 and CA-125 in (A) gynecologic cancers vs benign gynecologic diseases and (B) ovarian cancer vs other gynecologic diseases. A significantly higher area under the curve was observed with HE4 in comparison to CA-125 (0.875 vs $0.723, \mathrm{p}=0.0001$ and 0.903 vs $0.797, p=0.0003)$.

\section{Discussion}

In clinical practice, serial serum CA-125 measurements and ultrasonography are used as an aid to diagnose early ovarian cancer in asymptomatic post menopausal women. ${ }^{7,10,17}$ One major fallacy with using CA-125 as a screening tool is that about $20 \%$ of the ovarian tumors do not express the antigen..$^{7-10,17}$ It therefore seems prudent to combine CA-125 with new tumor marker(s) to increase its diagnostic efficacy. ${ }^{7,9,10,17,18}$

An important concern for CA 125 is its low diagnostic specificity. Several benign and malignant diseases, other than ovarian cancers may show abnormal CA-125 concentrations. ${ }^{7-11,19,20}$ This lack of specificity may be confounding in some benign gynecologic diseases such as endometriosis, commonly diagnosed in premenopausal women. Despite these controversies, CA 125 is still being used in the differential diagnosis of pelvic masses, assessment of response to treatment, and as a prognostic factor for early diagnosis of recurrence. ${ }^{7,8,10}$

HE4 protein is encoded by WAP four-disulfide core domain 2 (WFDC2) gene which is frequently over-expressed in ovarian carcinomas. ${ }^{14}$ In ovarian cancers, but not in normal tissue, this HE4 protein gets $\mathrm{N}$-glycosylated with an apparent molecular weight of $25 \mathrm{kDa}$. Then it is secreted into the extracellular environment to become detectable in the blood or urine of patients via

Table 3: Serum concentrations of HE4 and CA-125 in benign gynecologic diseases (Summary)

\begin{tabular}{lllllll}
\hline $\begin{array}{l}\text { Study participants } \\
(n)\end{array}$ & $\begin{array}{l}H E 4>140 \mathrm{pmol} / \mathrm{L} \\
n(\%)\end{array}$ & Median pmol/L & Range pmol/L & $\begin{array}{l}C A-125>35 \mathrm{kU} / \mathrm{L} \\
n(\%)\end{array}$ & Median $\mathrm{kU} / \mathrm{L}$ & Range $\mathrm{kU} / \mathrm{L}$ \\
\hline 146 & $2 / 146(1.3)$ & 46.5 & $4.6-320.7$ & $49 / 146(33.6)$ & 22 & $5-319$
\end{tabular}

Table 4: Serum concentrations of HE4 and CA-125 in benign gynecologic diseases

\begin{tabular}{llllllll}
\hline & $\begin{array}{l}\text { Study } \\
\text { participants }(n)\end{array}$ & $\begin{array}{l}H E 4>140 \\
\text { pmol/L }\end{array}$ & Median pmol/L & IQR pmol/L & CA-125>35 kU/L & Median kU/L & IQR kU/L \\
\hline Ovarian cysts & 72 & $0 / 72$ & 53.7 & $40.8-68.0$ & $20 / 72$ & 11.3 & $7.4-19.5$ \\
Fibroids & 29 & $1 / 29$ & 48.1 & $33.9-73.2$ & $12 / 29$ & 29.1 & $11.6-45.5$ \\
Endometriosis & 33 & $0 / 33$ & 40 & $34.3-50.7$ & $14 / 33$ & 25.5 & $10.7-54.9$ \\
Endometrial & & $0 / 06$ & 43.7 & $30.8-54.6$ & $02 / 06$ & 10.5 & $6.8-20.7$ \\
$\quad \begin{array}{l}\text { polyps } \\
\text { Others }\end{array}$ & 06 & $1 / 06$ & 43.9 & $37.5-52.5$ & $01 / 06$ & 9.8 & $5.7-15.9$ \\
\hline
\end{tabular}

$\mathrm{IQR}$, interquartile range 
Serum Human Epididymus Protein-4 (HE4) as a Biomarker in Ovarian Cancer

Table 5: Serum concentrations of HE4 and CA-125 in malignant gynecologic diseases

\begin{tabular}{llllllll}
\hline & Study participants $(n)$ & HE4 $>140$ pmol/L & Median pmol/L & IQR pmol/L & CA-125 >35 kU/L & Median kU/L & IQR kU/L \\
\hline Ovarian Ca & 64 & $48(75)$ & 357 & $17.2-7341$ & $51(80)$ & 154 & $2-8630$ \\
Endometrial Ca & 17 & $04(23.5)$ & 117.6 & $16.1-503.6$ & $09(53)$ & 179 & $3-8340$ \\
Endocervical Ca & 10 & $03(30)$ & 118.7 & $16-503.8$ & $05(50)$ & 169 & $3-8240$ \\
Sq cell Ca & 09 & 0 & 66.9 & $31-126$ & $02(22.2)$ & 22.2 & $10-649$ \\
\hline
\end{tabular}

Sq cell Ca, squamous cell carcinoma

Table 6: Serum HE4 and CA-125 in patients with ovarian cancer (excluding those with RF or creatinine $>1.3 \mathrm{mg} / \mathrm{DL}$ ) $64-1=63$

\begin{tabular}{|c|c|c|c|c|c|c|c|c|c|}
\hline & $\begin{array}{l}\text { HE4>140 } \\
\mathrm{pmol} / \mathrm{L} \\
\mathrm{n} / \mathrm{N} \%\end{array}$ & $\begin{array}{l}\text { Median (SE) } \\
\mathrm{pmol} / \mathrm{L}\end{array}$ & $\begin{array}{l}\text { Range } \\
\mathrm{pmol} / \mathrm{L}\end{array}$ & $\begin{array}{l}95^{\text {th }} \\
\text { percentile } \\
\text { pmol/L }\end{array}$ & $\begin{array}{l}C A-125>35 \\
k U / L n / N \%\end{array}$ & $\begin{array}{l}\text { Median (SE) } \\
\mathrm{kU} / \mathrm{L}\end{array}$ & $\begin{array}{l}\text { Range } \\
k U / L\end{array}$ & $\begin{array}{l}\text { 95th } \\
\text { percentile } \\
\mathrm{kU} / \mathrm{L}\end{array}$ & $\begin{array}{l}\text { One or both } \\
\text { positive n/N\% }\end{array}$ \\
\hline Stage I-II (N = 12) & $7 / 12(58.3)$ & $193.4(47.3)$ & $45-954.1$ & 902 & $6 / 12(50)$ & $38.1(27.5)$ & $7-514$ & 485.5 & $9 / 12(75)$ \\
\hline Stage III $(\mathrm{N}=26)$ & $21 / 26(80.1)$ & $415.3(82.8)$ & $17.2-2787$ & 1916.3 & $22 / 26(84.6)$ & $162(191.7)$ & $2-8630$ & 3367.3 & 25/26 (96.2) \\
\hline Stage IV (N = 25) & $20 / 25(80)$ & $501.6(157.1)$ & $22-7341$ & 2090 & $21 / 25(84)$ & $366(175.6)$ & 10-735 & 2801.5 & $24 / 25(96)$ \\
\hline Serous $(N=45)$ & $38 / 45(84.4)$ & 492 95.3) & $17.2-7341$ & 2083.6 & $38 / 45(84.4)$ & $220.5(143.4)$ & $2-8630$ & 3225.8 & 44/45 (97.7) \\
\hline Mucinous ( $\mathrm{N}=8$ ) & $04 / 08(50)$ & $109.2(43.6)$ & $25-636.4$ & 636.4 & $05 / 08(62.5)$ & $62(36.2)$ & $8-514$ & 514 & 06/08 (75) \\
\hline Others $(\mathrm{N}=10)$ & $06 / 10(60)$ & $153.6(96.1)$ & $43.2-1651$ & 1651 & 06/10 (60) & 75 (131.8) & $7-2210$ & 2210 & 07/10 (70) \\
\hline
\end{tabular}

enzyme immunoassay[16, 20]. It is highly stable on a wide range of $\mathrm{pH}$ and temperature. Other tissues like lung, endometrial, and breast adenocarcinomas, mesotheliomas, and rarely, kidney gastrointestinal, and transitional cell cancers have also reported some expression. ${ }^{18,19}$ Previous studies indicate that normal ranges for HE4 are 51.3- $78.4 \mathrm{pmol} / \mathrm{l}$ (females) and 43.4-69.7 pmol/L (males). ${ }^{21,22}$

We found that HE4 serum concentrations were less likely to be increased in benign gynecologic conditions than CA-125. Here HE4 was increased in only $1.3 \%(2 / 146)$ of patients with benign gynecologic disease where as CA 125 showed an increase in $33.6 \%(49 / 146)$ of patients with benign gynecologic conditions. None of our 33 patients with endometriosis had high HE4 serum levels whereas $42.4 \%$ patients had high CA 125 concentrations. These results establish the correctness of previously published findings and distinctly prove the usefulness of HE4 in the differential diagnosis of ovarian carcinoma from other gynecologic conditions. ${ }^{9,11-15,21-25}$

Similar to other tumor markers, renal failure is the most important source of false positivity during the exposition of HE4 results. So, in patients with renal failure or those with abnormal serum creatinine concentrations, HE4 results should be interpreted cautiously. ${ }^{26,27}$ This is vital, because acute renal failure may be found in some patients undergoing chemotherapy. Therefore we excluded 1 ovarian cancer patient with renal failure from our study.

HE4 has been advocated as a promising biomarker for ovarian cancer. HE4 showed higher median concentrations and diagnostic sensitivity in ovarian carcinoma than the clinically more popular CA-125. Our data corroborate with previous studies of HE4 in ovarian or gynecologic tumors. Minor differences observed may be due to population characteristics. ${ }^{9}$

Both HE4 and CA-125 were well-related to the tumor stage and histological type. Diagnostic sensitivity of HE4 was similar or higher than CA-125 in early stages, and CA-125 showed marginally higher sensitivity in advanced stages. Significantly higher differences in the median concentrations were observed for both HE4 and CA-125 in early stages than in advanced disease. This may be due to the lower concentrations of the biomarkers in the early stages. The point to consider is that both the biomarkers are complementary showing much higher diagnostic sensitivity in combination. Nonetheless, the specificity of the combination dropped due to the high CA-125 false positivity in other gynecologic conditions, especially in premenopausal women.

ROC curve shows the higher HE4 diagnostic specificity and similar diagnostic sensitivity compared with CA-125, accounting for the more pragmatic approach of HE4 in the differential diagnosis of gynecologic diseases. ${ }^{9,15}$

\section{Limitations}

These are hospital referred patients, so do not necessarily represent the true distribution of cancer subtypes. Reference levels for the Indian population could be calculated and used for better diagnostic performances of serum HE4.

One well recognized source of false-positivity with CA-125 is the presence of effusions. Studies have shown that effusions had less influence on HE4 results than on CA $125^{29}$ but we have not evaluated patients with benign or malignant effusions separately.

Abnormal serum concentrations have also been reported in other non-gynecologic cancers like Non small cell lung carcinoma (NSCLC) , liver cancers. ${ }^{27,30}$ So we humbly understand that there is scope of further studies on these aspects.

\section{Conclusion}

HE4 showed higher diagnostic specificity than CA-125 in benign gynecologic diseases. It demonstrated its usefulness in the differential diagnosis of ovarian from non-ovarian gynecologic cancers. It was well related to the stage and histological type and the combination of HE4 with CA-125 enhanced the diagnostic sensitivity for ovarian tumors.

\section{Funding: None}

Conflicting Interest: This is to certify that the study "Serum Human Epididymus protein-4 (HE4) as a biomarker in ovarian cancer and its comparison with CA-125 in benign and malignant cases " has no potential, perceived, or real competing and/or conflicts of interest with the other departments and members involved in the same study.

Ethical approval: The study was duly approved by the Institutional research committee. All the ethical guidelines and standards were followed. Prior written informed consent was obtained from all the participants. 


\section{References}

1. Three year report of population based cancer registries 2012-2014: Incidence, distribution, trends in incidence rates and projections of burden of cancer . [Internet]. Bengaluru, India: national Centre for Disease Informatics and Research, National Cncer Registry Programme, and Indian Council of Medical research [cited 2016 May 2016]. Available from: http://www.ncrpindia.org/ALL_NCRP_ REPORTS/PBCR_REPORT_2012_2014/ALL_CONTENT/Printed _Version.htm

2. National Institutes of Health. National Cancer Institute. Surveillance, Epidemiology, and End Results Program. Statistical summaries: cancer stat fact sheets (ovary) and cancer statistics review (CSR), 1975-2013. http:// seer.cancer.gov/statistics/summaries.html.

3. Clarke-Pearson DL. Clinical practice. Screening for ovarian cancer. $N$ Eng/ J Med. 2009;361(2):170-177.

4. Jelovac D, Armstrong DK. Recent progress in the diagnosis and treatment of ovarian cancer. CA Cancer J Clin. 2011;61(3):183-203.

5. American Cancer Society. Ovarian cancer. 2014. http://www.cancer. org/acs/groups/cid/documents/webcontent/003130-pdf.pdf. Accessed March 8, 2016.

6. Prat J; FIGO Committee on Gynecologic Oncology. Staging classification for cancer of the ovary, fallopian tube, and peritoneum. Int J Gynaecol Obstet. 2014;124(1):1-5. .

7. Bast RC Jr, Badgwell D, Lu Z, Marquez R, Rosen D, Liu J, et al. New tumor markers: CA-125 and beyond. Int J Gynecol Cancer 2005;15(Suppl 3): 274-281.

8. Sturgeon CM, Duffy MJ, Stenman UH, Lilja H, Brunner N, Chan DW, et al. National Academy of Clinical Biochemistry laboratory medicine practice guidelines for use of tumor markers in testicular, prostate, colorectal, breast, and ovarian cancers. Clin Chem 2008;54:e11-79.

9. Moore RG, McMeekin DS, Brown AK, DiSilvestro P, Miller MC, Allard WJ, et al. A novel multiple marker bioassay utilizing HE4 and CA-125 for the prediction of ovarian cancer in patients with a pelvic mass. Gynecol Oncol 2009;112:40-6.

10. Duffy MJ, Bonfrer JM, Kulpa J, Rustin GJ, Soletormos G, Torre GC, et al. CA-125 in ovarian cancer: European Group on Tumor Markers guidelines for clinical use. Int J Gynecol Cancer 2005;15:679 -691.

11. Anastasi E, Granato T, Marchei GG, Viggiani V, Colaprisca B, Comploj $\mathrm{S}$, et al. Ovarian tumor marker HE4 is differently expressed during the phases of the menstrual cycle in healthy young women. Tumour Biol 2010;31:411-415.

12. Moore RG, Jabre-Raughley M, Brown AK, Robison KM, Miller MC, Allard WJ, et al. Comparison of a novel multiple marker assay vs the Risk of Malignancy Index for the prediction of epithelial ovarian cancer in patients with a pelvic mass. Am J Obstet Gynecol 2010;203:228.

13. Nolen B, Velikokhatnaya L, Marrangoni A, De Geest K, Lomakin A, Bast RC Jr, Lokshin A. Serum biomarker panels for the discrimination of benign from malignant cases in patients with an adnexal mass. Gynecol Oncol 2010;117:440-445.

14. Bingle L, Singleton V, Bingle CD. The putative ovarian tumour marker gene HE4 (WFDC2), is expressed in normal tissues and undergoes complex alternative splicing to yield multiple protein isoforms. Oncogene 2002;21:2768-2773.
15. Galgano MT, Hampton GM, Frierson HF Jr. Comprehensive analysis of HE4 expression in normal and malignant human tissues. Mod Pathol 2006; 19:847-853.

16. Drapkin R, von Horsten HH, Lin Y, Mok SC, Crum CP, Welch WR, Hecht JL. Human epididymis protein 4 (HE4) is a secreted glycoprotein that is overexpressed by serous and endometrioid ovarian carcinomas. Cancer Res 2005;65:2162-2169.

17. Montagnana M, Lippi G, Danese E, Franchi M, Guidi GC. Usefulness of serum HE4 in endometriotic cysts. Br J Cancer 2009;101:548.

18. van Dalen A, Favier J, Hallensleben E, Burges A, Stieber P, de Bruijn $\mathrm{HW}$, et al. Significance of serum CA-125 and TPS antigen levels for determination of overall survival after three chemotherapy courses in ovarian cancer patients during long-term follow-up. Eur J Gynaecol Oncol 2009; 30:609-615.

19. Molina R, Auge JM, Bosch X, Escudero JM, Vinolas N, Marrades R, et al. Usefulness of serum tumor markers, including progastrin-releasing peptide, in patients with lung cancer: correlation with histology. Tumour Biol 2009;30:121-129.

20. Hellstrom I, Heagerty PJ, Swisher EM, Liu P, Jaffar J, Agnew K, Hellstrom $\mathrm{KE}$. Detection of the HE4 protein in urine as a biomarker for ovarian neoplasms. Cancer Lett 2010;296:43- 48.

21. Karlsen NS, Karlsen MA, Høgdall CK, Høgdall EV. HE4 tissue expression and serum HE4 levels in healthy individuals and patients with benign or malignant tumors: a systematic review. Cancer Epidemiol Biomarkers Prev. $2014 ; 23: 2285-2295$

22. Park Y, Kim Y, Lee EY, Lee JH, Kim HS. Reference ranges for HE4 and CA-125 in a large Asian population by automated assays and diagnostic performances for ovarian cancer. Int J Cancer. 2012;130:1136-1144

23. Anastasi E, Marchei GG, Viggiani V, Gennarini G, Frati L, Reale MG. HE4: a new potential early biomarker for the recurrence of ovarian cancer. Tumour Biol 2010;31:113-119.

24. Huhtinen K, Suvitie P, Hiissa J, Junnila J, Huvila J, Kujari H, et al. Serum HE4 concentration differentiates malignant ovarian tumours from ovarian endometriotic cysts. Br J Cancer 2009;100: 1315-1319.

25. Goff BA, Agnew K, Neradilek MB, Gray HJ, Liao JB, Urban RR . Combining a symptom index, CA-125 and HE4 (triple screen) to detect ovarian cancer in women with a pelvic mass. Gynecol Oncol. 2017;147:291-295

26. Yuan T, Li Y. Human Epididymis Protein 4 as a Potential Biomarker of Chronic Kidney Disease in Female Patients With Normal Ovarian Function. Lab Med. 2017;48:238-243.

27. Jose ME, Jose MA, Xavier F, Aureli T, Jaume P, Rafael M. Comparison of Serum Human Epididymis Protein 4 with Cancer Antigen 125 as a Tumor Marker in Patients with Malignant and Nonmalignant Diseases. Clin Chemistry 2011; 57:1534-1544.

28. Leung F, Bernardini MQ, Brown MD, Zheng Y, Molina R, Bast RC Jr, Davis $\mathrm{G}$ et al. Validation of a Novel Biomarker Panel for the Detection of Ovarian Cancer. Cancer Epidemiol Biomarkers Prev. 2016;25:1333-1340

29. Hellstrom I, Hellstrom KE. SMRP and HE4 as biomarkers for ovarian carcinoma when used alone and in combination with CA-125 and/ or each other. Adv Exp Med Biol 2008;622:15-21.

30. Lamy PJ, Plassot C, Pujol JL. Serum HE4: An Independent Prognostic Factor in Non-Small Cell Lung Cancer. PLoS One. 2015 ;10(6). 